\title{
The effect of biological agent treatment on neutrophil- to-lymphocyte ratio, platelet-to-lymphocyte ratio, mean platelet volume, and C-reactive protein in psoriasis patients
}

\author{
Isa An ${ }^{1}$, Derya Ucmak ${ }^{2}$, Murat Ozturk ${ }^{3}$ \\ ${ }^{1}$ Department of Dermatology, Sanlıurfa Training and Research Hospital, Sanlıurfa, Turkey \\ ${ }^{2}$ Department of Dermatology, Medical Faculty, Dicle University, Diyarbakır, Turkey \\ ${ }^{3}$ Department of Dermatology, Van Training and Research Hospital, Van, Turkey
}

\begin{abstract}
Introduction: In recent years, the neutrophil/lymphocyte ratio (NLR), platelet/lymphocyte ratio (PLR), mean platelet volume (MPV) and C reactive protein (CRP) have been shown to be important indicators of systemic inflammation. Studies have shown that NLR, PLR, MPV and CRP are higher in psoriasis patients than in the control group.

Aim: To investigate the NLR, PLR, MPV and serum CRP levels in patients who were treated with biological agents for psoriasis.

Material and methods: In our study, 75 patients who were followed up and had a diagnosis of psoriasis vulgaris and took a biological agent therapy between January 2014 and December 2017 in the Dermatology Clinic of the Dicle University Medical Faculty Hospital were evaluated before treatment, and 3 and 6 months after treatment. Results: Neutrophil count, lymphocyte count, thrombocyte count, NLR, PLR, MPV and CRP values before the biological agent treatment were statistically higher than the values at 3 and 6 months of treatment. There was no statistically significant difference between pre-treatment neutrophil, lymphocyte, leukocyte, platelet, NLR, PLR, MPV, CRP values and values at 3 and 6 months after treatment when we compared four different biological agents.

Conclusions: It was seen that NLR, PLR, MPV and CRP values decreased independently of the type of the biological agent used in our study. Therefore, we think that these parameters can be used to evaluate the effects of biological agent treatment on systemic inflammation in psoriasis patients and to monitor the course of the disease.
\end{abstract}

Key words: mean platelet volume, neutrophil-to-lymphocyte ratio, platelet-to-lymphocyte ratio.

\section{Introduction}

Psoriasis is a common chronic inflammatory and proliferative skin disease in which genetic and environmental factors play a critical role [1, 2]. The inflammatory nature of the disease is caused by overexpression of tumour necrosis factor tumor necrosis factor $\alpha$ (TNF- $\alpha$ ), interferon $\gamma($ IFN- $\gamma)$ and various proinflammatory cytokines [2, 3].

In recent years, the neutrophil/lymphocyte ratio (NLR), platelet/lymphocyte ratio (PLR), mean platelet volume (MPV) and $C$ reactive protein (CRP) have been shown to be important indicators of systemic inflammation [4-7]. NLR and PLR were found to be associated with interleukin IL- 6 and TNF- $\alpha$, which play an important role in the pathogenesis of psoriasis $[8,9]$.

Studies have shown that NLR, PLR, MPV and CRP are higher in psoriasis patients than in the control group [8, 10-12].

\section{Aim}

In our study, we aimed to investigate the NLR, PLR, MPV and serum CRP levels, which are cheap and easily applicable parameters in evaluating the response to systemic treatment, in patients who were treated with biological agents for psoriasis.

Address for correspondence: Isa An MD, Department of Dermatology, Sanlıurfa Training and Research Hospital, Sanlıurfa, Turkey, e-mail: is_an89@hotmail.com

Received: 1.08.2018, accepted: 2.10.2018. 


\section{Material and methods}

\section{Patients and study design}

In our study, 75 patients who were followed up who had a diagnosis of psoriasis vulgaris (PV) and took a biological agent therapy between January 2014 and December 2017 in the Dermatology Clinic of Dicle University Medical Faculty Hospital were evaluated before treatment, and 3 and 6 months after treatment. Patients with moderate-to-severe plaque-type psoriasis vulgaris who did not respond to conventional systemic treatments such as acitretin, methotrexate, and cyclosporine or whose conventional systemic treatment was contraindicated were included in the study. Age, sex, duration of disease, presence of arthritis, nail involvement, neutrophil, lymphocyte, leukocyte, thrombocyte, NLR, PLR, MPV and CRP values were recorded.

The NLR value was calculated by dividing the number of neutrophils by the number of lymphocytes and the PLR value by dividing the number of platelets by the number of lymphocytes. Complete blood count was performed with Cell-Dyn 3700 (optical scatter laser method, Abbott Diagnostics, Chicago, USA). The CRP level was measured by Beckman Coulter nephelometric method (IMMAGE 800, USA).

\section{Treatments}

Infliximab was administered i.v. (5 mg/kg) at weeks 0, 2, 6 and thereafter every 8 weeks. Adalimumab was administered s.c. (80 mg) at week 0 and 1 and thereafter at $40 \mathrm{mg}$ every 2 weeks. Etanercept was administered s.c. $(2 \times 25 \mathrm{mg}$ or $2 \times 50 \mathrm{mg})$ at week 1 and thereafter every week. Ustekinumab was administered s.c. (45 or $90 \mathrm{mg}$ ) at weeks 0, 4 and thereafter every 12 weeks.

Patients who had another skin disease, cardiovascular, gastrointestinal, renal disease, malignancy, diabetes mellitus, infectious and inflammatory disease, and patients not taking the recommended treatment protocol were excluded.

\section{Statistical analysis}

Values of the data were taken as pre-treatment- $3^{\text {rd }}$ month and $6^{\text {th }}$ month of treatment. In statistical analysis of these data, the variance analysis method was applied in repeated measures. The interaction between time measurements was looked at and compared. A statistically significant result was accepted if $p<0.05$. Statistical analyses were performed using the SPSS 21.0 for Windows (SPSS Inc., Chicago, IL, USA) package program.

\section{Results}

In this study, the results of $75 \mathrm{PV}$ patients before the biological agent treatment and 3 and 6 months after treatment were evaluated.

The mean age of PV patients was $38.7 \pm 14.8$ years. Thirty-eight (50.6\%) of PV patients were male and 37 (49.4\%) were female. The mean disease duration of PV patients was $16.0 \pm 8.7$ years.

Forty-eight (64\%) of the PV patients had nail involvement and 11 (14.6\%) had arthritis. Eighteen (24\%) of the PV patients had family history. Thirty-four patients received adalimumab, 20 patients infliximab, 11 patients etanercept, and 10 patients ustekinumab.

Table 1. Pre-treatment, $3^{\text {rd }}$ and $6^{\text {th }}$ month laboratory results of the patients

\begin{tabular}{|c|c|c|c|c|}
\hline Parameter & $\begin{array}{c}\text { Pre-treatment } \\
\text { Mean } \pm \text { SD } \\
\text { Median (min.-max.) }\end{array}$ & $\begin{array}{l}\text { After treatment ( } 3^{\text {rd }} \text { month) } \\
\text { Mean } \pm \text { SD } \\
\text { Median (min.-max.) }\end{array}$ & $\begin{array}{l}\text { After treatment ( } 6^{\text {th }} \text { month) } \\
\text { Mean } \pm \text { SD } \\
\text { Median (min.-max.) }\end{array}$ & $P$-value \\
\hline Neutrophil $\left[\times 10^{3} / \mathrm{ml}\right]$ & $\begin{array}{c}4.59 \pm 1.31 \\
4.65(1.83-6.74)\end{array}$ & $\begin{array}{c}4.64 \pm 1.27 \\
4.65(2.54-6.72)\end{array}$ & $\begin{array}{c}4.63 \pm 1.27 \\
4.64(2.53-6.64)\end{array}$ & $<0.001$ \\
\hline Lymphocytes $\left[\times 10^{3} / \mathrm{ml}\right]$ & $\begin{array}{c}3.27 \pm 1.72 \\
2.86(1.36-9.60)\end{array}$ & $\begin{array}{c}2.84 \pm 1.53 \\
2.71(1.36-9.60)\end{array}$ & $\begin{array}{c}2.86 \pm 1.53 \\
2.72(1.37-9.62)\end{array}$ & $<0.001$ \\
\hline Leukocytes $\left[\times 10^{3} / \mathrm{ml}\right]$ & $\begin{array}{c}6.80 \pm 2.50 \\
7.81(1.37-9.54)\end{array}$ & $\begin{array}{c}7.89 \pm 1.24 \\
8.13(5.54-9.55)\end{array}$ & $\begin{array}{c}7.88 \pm 1.23 \\
8.14(5.54-9.58)\end{array}$ & 0.077 \\
\hline Platelets $\left[\times 10^{3} / \mathrm{ml}\right]$ & $\begin{array}{c}327.34 \pm 83.08 \\
321.00(162.60-459.12)\end{array}$ & $\begin{array}{c}326.78 \pm 83.82 \\
318.65(160.00-455.87)\end{array}$ & $\begin{array}{c}323.62 \pm 86.17 \\
317.45(157.84-455.00)\end{array}$ & $<0.001$ \\
\hline NLR & $\begin{array}{c}1.78 \pm 1.02 \\
1.41(0.32-4.08)\end{array}$ & $\begin{array}{c}2.00 \pm 1.04 \\
1.73(0.44-4.89)\end{array}$ & $\begin{array}{c}1.98 \pm 1.03 \\
1.72(0.44-4.85)\end{array}$ & $<0.001$ \\
\hline PLR & $\begin{array}{c}123.14 \pm 62.83 \\
99.76(28.56-294.31)\end{array}$ & $\begin{array}{c}136.97 \pm 61.44 \\
135.31(28.03-290.37)\end{array}$ & $\begin{array}{c}134.56 \pm 61.12 \\
133.67(27.80-288.71)\end{array}$ & $<0.001$ \\
\hline MPV & $\begin{array}{c}9.72 \pm 0.79 \\
9.76(7.0-11.7)\end{array}$ & $\begin{array}{c}9.60 \pm 0.75 \\
9.72(6.9-11.4)\end{array}$ & $\begin{array}{c}9.45 \pm 0.77 \\
9.57(6.4-11.3)\end{array}$ & $<0.001$ \\
\hline CRP $[\mathrm{mg} / \mathrm{dl}]$ & $\begin{array}{c}0.84 \pm 0.37 \\
0.78(0.21-1.74)\end{array}$ & $\begin{array}{c}0.55 \pm 0.21 \\
0.48(0.19-0.95)\end{array}$ & $\begin{array}{c}0.38 \pm 0.16 \\
0.31(0.11-0.84)\end{array}$ & $<0.001$ \\
\hline
\end{tabular}


Table 2. Change of inflammatory parameters according to biological agents

\begin{tabular}{|c|c|c|c|c|c|}
\hline Parameter & Biological agent & $\begin{array}{l}\text { Pre-treatment } \\
\text { Mean } \pm \text { SD }\end{array}$ & $\begin{array}{c}\text { After treatment } \\
\left(3^{\text {rd }} \text { month }\right) \\
\text { Mean } \pm \text { SD }\end{array}$ & $\begin{array}{l}\text { After treatment } \\
\left(6^{\text {th }} \text { month }\right) \\
\text { Mean } \pm \text { SD }\end{array}$ & $P$-value \\
\hline \multirow[t]{4}{*}{ Neutrophil $\left[\times 10^{3} / \mathrm{ml}\right]$} & Etanercept & $4.70 \pm 1.25$ & $4.88 \pm 0.68$ & $4.86 \pm 0.69$ & \multirow{4}{*}{0.725} \\
\hline & Adalimumab & $4.65 \pm 1.35$ & $4.62 \pm 1.45$ & $4.61 \pm 1.45$ & \\
\hline & Infliximab & $4.40 \pm 1.45$ & $4.59 \pm 1.35$ & $4.59 \pm 1.34$ & \\
\hline & Ustekinumab & $4.60 \pm 1.11$ & $4.53 \pm 1.05$ & $4.52 \pm 1.05$ & \\
\hline \multirow[t]{4}{*}{ Lymphocyte $\left[\times 10^{3} / \mathrm{ml}\right]$} & Etanercept & $3.23 \pm 1.25$ & $2.64 \pm 0.81$ & $2.66 \pm 0.79$ & \multirow{4}{*}{0.843} \\
\hline & Adalimumab & $3.01 \pm 1.47$ & $2.61 \pm 1.17$ & $2.62 \pm 1.17$ & \\
\hline & Infliximab & $3.58 \pm 2.05$ & $3.16 \pm 1.91$ & $3.19 \pm 1.91$ & \\
\hline & Ustekinumab & $3.55 \pm 2.28$ & $3.20 \pm 2.30$ & $3.22 \pm 2.30$ & \\
\hline \multirow[t]{4}{*}{ Leukocyte $\left[\times 10^{3} / \mathrm{ml}\right]$} & Etanercept & $6.32 \pm 2.77$ & $8.15 \pm 0.99$ & $8.15 \pm 0.97$ & \multirow{4}{*}{0.762} \\
\hline & Adalimumab & $6.69 \pm 2.62$ & $7.82 \pm 1.32$ & $7.82 \pm 1.31$ & \\
\hline & Infliximab & $7.30 \pm 2.25$ & $7.98 \pm 1.31$ & $7.98 \pm 1.31$ & \\
\hline & Ustekinumab & $6.68 \pm 2.50$ & $7.64 \pm 1.19$ & $7.61 \pm 1.16$ & \\
\hline \multirow[t]{4}{*}{ Platelet $\left[\times 10^{3} / \mathrm{ml}\right]$} & Etanercept & $312.89 \pm 97.39$ & $313.35 \pm 96.28$ & $311.78 \pm 95.38$ & \multirow{4}{*}{0.419} \\
\hline & Adalimumab & $337.94 \pm 84.23$ & $337.36 \pm 85.30$ & $331.97 \pm 90.98$ & \\
\hline & Infliximab & $320.81 \pm 65.88$ & $319.92 \pm 67.47$ & $318.47 \pm 67.57$ & \\
\hline & Ustekinumab & $320.29 \pm 101.04$ & $319.26 \pm 101.81$ & $318.59 \pm 102.15$ & \\
\hline \multirow[t]{4}{*}{ NLR } & Etanercept & $1.82 \pm 1.17$ & $2.09 \pm 0.97$ & $2.05 \pm 0.96$ & \multirow{4}{*}{0.779} \\
\hline & Adalimumab & $1.93 \pm 1.10$ & $2.13 \pm 1.15$ & $2.12 \pm 1.15$ & \\
\hline & Infliximab & $1.61 \pm 0.96$ & $1.86 \pm 1.03$ & $1.84 \pm 1.01$ & \\
\hline & Ustekinumab & $1.58 \pm 0.70$ & $1.73 \pm 0.71$ & $1.72 \pm 0.71$ & \\
\hline \multirow{4}{*}{ PLR } & Etanercept & $108.68 \pm 46.98$ & $129.06 \pm 52.94$ & $126.93 \pm 52.49$ & \multirow{4}{*}{0.836} \\
\hline & Adalimumab & $136.57 \pm 68.22$ & $149.63 \pm 63.96$ & $146.38 \pm 64.34$ & \\
\hline & Infliximab & $110.50 \pm 49.93$ & $123.25 \pm 52.74$ & $121.32 \pm 51.53$ & \\
\hline & Ustekinumab & $118.66 \pm 79.77$ & $130.09 \pm 76.77$ & $129.25 \pm 76.49$ & \\
\hline \multirow[t]{4}{*}{ MPV } & Etanercept & $9.88 \pm 0.85$ & $9.69 \pm 0.76$ & $9.51 \pm 0.74$ & \multirow{4}{*}{0.140} \\
\hline & Adalimumab & $9.65 \pm 0.94$ & $9.55 \pm 0.92$ & $9.36 \pm 0.98$ & \\
\hline & Infliximab & $9.71 \pm 0.63$ & $9.63 \pm 0.56$ & $9.54 \pm 0.53$ & \\
\hline & Ustekinumab & $9.80 \pm 0.45$ & $9.66 \pm 0.39$ & $9.49 \pm 0.24$ & \\
\hline \multirow[t]{4}{*}{ CRP $[\mathrm{mg} / \mathrm{dl}]$} & Etanercept & $0.98 \pm 0.37$ & $0.6 \pm 10.20$ & $0.35 \pm 0.10$ & \multirow{4}{*}{0.440} \\
\hline & Adalimumab & $0.80 \pm 0.36$ & $0.56 \pm 0.23$ & $0.39 \pm 0.20$ & \\
\hline & Infliximab & $0.87 \pm 0.33$ & $0.55 \pm 0.19$ & $0.37 \pm 0.14$ & \\
\hline & Ustekinumab & $0.79 \pm 0.50$ & $0.49 \pm 0.20$ & $0.37 \pm 0.14$ & \\
\hline
\end{tabular}

Neutrophil count, lymphocyte count, thrombocyte count, NLR, PLR, MPV and CRP values before the biological agent treatment were statistically higher than the values at 3 and 6 months of treatment $(p<0.001)$ (Table 1).

The difference between the leukocyte values before the biological agent treatment of the and the values at 3 and 6 months after the treatment was not statistically significant $(p=0.077)$.

There was no statistically significant difference between pre-treatment neutrophil, lymphocyte, leukocyte, platelet, NLR, PLR, MPV, CRP values and at 3 and 6 months after the treatment when we compared four different biological agents $(p>0.05)$ (Table 2$)$.

\section{Discussion}

Psoriasis is a chronic inflammatory disease that affects the knees, elbows and extensor side of the extremities, which occurs in about $2-3 \%$ of the population [13,
14]. Psoriasis is thought to be a result of complicated relationships between T-lymphocytes, neutrophils, macrophages, mast cells, keratinocytes and dendritic cells [14]. Neutrophils initiate the first step of systemic inflammation and show nonspecific inflammation. Detection of increased neutrophils with neutrophil activation products in psoriatic lesions and peripheral blood and induction of psoriasis with neutrophil-derived IL-1 $\beta$ and TNF- $\alpha$ supports the opinion that neutrophils play an active role in the pathogenesis of psoriasis [14, 15].

Rocha-Pereira et al. reported an increased number of neutrophils in psoriasis patients and found that the number of neutrophils was significantly higher in patients with active psoriasis than in inactive patients [16]. Yamanaka et al. showed that biological agent treatments did not significantly alter IFN- $\gamma$, IL-17 and TNF- $\alpha$ production from lymphocytes in patients with severe psoriasis, but blocked neutrophil activation in patients. In addition, there was no difference between infliximab and 
ustekinumab in terms of decreased neutrophil activity after treatment with a biological agent [17].

Similarly, in our study, it was observed that the number of neutrophils decreased independently of the type of the biological agent.

NLR is an inexpensive, easy-to-use inflammatory marker that is obtained by dividing the total number of neutrophils by the number of lymphocytes. NLR has been shown to increase in many diseases such as metabolic syndrome, ankylosing spondylitis, rheumatoid arthritis, vitiligo and lichen planus [1, 4, 5, 18-20]. Increased levels of several cytokines such as TNF- $\alpha$, IL-6, IL-12 and IL-17 in psoriasis have been shown to cause elevation in NLR [8].

Kim et al. showed that NLR was increased in psoriatic patients compared to the control group and there was a positive correlation between PASI score and NLR20. Erek Toprak et al. reported that NLR levels were not affected after 3 months of phototherapy in patients with psoriasis, and this was probably due to the presence of residual inflammation [21]. Asahina et al. have shown that NLR had decreased in patients with psoriasis after 12 months of treatment with biological agents and there is no difference between treatments used. It has also been reported that NLR may be used to assess systemic inflammation and monitor disease course after treatment [22].

In our study, after 6 months of treatment with a biological agent, NLR was found to be reduced independently of the type of the biological agent used.

Platelets play a role in many processes such as inflammation and immunity $[23,24]$. PLR is obtained by dividing the platelet count by the lymphocyte count. In recent years it has been reported that PLR value may be a marker of systemic inflammation [8, 18, 22]. Unal et al. found that PLR values were significantly higher in patients with psoriasis than in the control group. In this study, it was also stated that PLR may be a better inflammatory parameter than NLR [8].

Boyraz et al. have detected significantly lower levels of PLR in patients with ankylosing spondylitis treated with anti-TNF- $\alpha$ than in the control group and have also indicated that PLR can be used as an appropriate marker to monitor disease progression [18]. Asahina et al. reported that the PLR value was significantly decreased after treatment with any of the infliximab, adalimumab and ustekinumab in psoriatic patients, but the mean reduction rate was found to be numerically lower in ustekinumab treatment than infliximab and adalimumab treatments [22]. In our study, it was observed that the PLR values decreased independently of the type of the biological agent used.

MPV is considered an in vivo marker of platelet reactivity. Many studies have suggested that MPV plays an important role as a marker of inflammation and shows disease activity and anti-inflammatory treatment efficacy in chronic inflammatory diseases $[6,12,25]$. Canpolat et al. showed MPV has a positive correlation with PASI score in patients with psoriasis and that MPV was higher in patients with psoriatic arthritis than in those without arthritis [26].

In a study, anti-TNF- $\alpha$ therapy was started for 21 patients with rheumatoid arthritis who did not have cardiovascular disease, and the values of MPV were measured before treatment and at the $2^{\text {nd }}$ and $12^{\text {th }}$ weeks of treatment. Anti-TNF- $\alpha$ treatment has been shown to cause a significant increase in MPV over the course of treatment [19].

Asahina et al. reported that MPV values did not change significantly after treatment in patients with psoriasis who received biological agents but a significant increase was observed at some time points after treatment with infliximab or adalimumab in psoriatic arthritis patients [22].

In our study, we observed that, unlike the data in the literature show, there was a decrease in MPV values independently of the type of the biological agent used. Like NLR and PLR, we think that MPV can also be used to evaluate the effects of biological agent treatment on systemic inflammation.

CRP is an acute phase protein that is produced predominantly by hepatocytes by the action of cytokines such as IL-6 and TNF- $\alpha$ [27]. It has been shown that serum CRP levels increase in psoriasis patients and that there is a positive correlation between CRP levels and disease severity [10].

Strober et al. reported that after treatment with etanercept a significant reduction in CRP levels was shown at third month of treatment and this reduction may be due to IL-6 inhibition [7]. In a study, CRP levels were significantly reduced when adalimumab was administered to patients with psoriasis with suboptimal response to etanercept, methotrexate, and db UVB treatment [28].

Asahina et al. have shown in psoriasis patients that TNF- $\alpha$ antagonists (infliximab and adalimumab) inhibit CRP more than IL-12/23 p40 antagonist (ustekinumab) [29]. Since TNF- $\alpha$ is required for CRP synthesis, inhibition of CRP by TNF- $\alpha$ antagonists is mainly due to the direct effects of TNF- $\alpha$ on CRP [22].

In our study, the CRP values before biological agent treatment were statistically significantly higher than the values at 3 and 6 months of treatment. When etanercept, adalimumab, infliximab, and ustekinumab treatments were compared, there was no statistically significant difference between CRP values before treatment and values at 3 and 6 months of treatment.

\section{Conclusions}

It was seen that NLR, PLR, MPV and CRP values decreased independently of the type of the biological agent used in our study. Therefore, we think that these parameters can be used to evaluate the effects of biological agent 
treatment on systemic inflammation in psoriasis patients and to monitor the course of the disease.

\section{Acknowlegments}

We would like to thank Dr. Ismail Yıldız for his help in statistical analysis.

\section{Conflicts of interest}

The authors declare no conflict of interest.

\section{References}

1. Cemil BC, Ataş H. The effect of biological treatment onto systemic inflammatory markers and plateletcrit in psoriasis patients. Dicle Med J 2016; 43: 477-83.

2. Stawczyk-Macieja M, Szczerkowska-Dobosz A, Rębała K, Purzycka-Bohdan D. Genetic background of skin barrier dysfunction in the pathogenesis of psoriasis vulgaris. Adv Dermatol Allergol 2015; 32: 123-6.

3. Zabłotna M, Sobjanek M, Purzycka-Bohdan D, et al. The significance of Toll-like receptor (TLR) 2 and 9 gene polymorphisms in psoriasis. Adv Dermatol Allergol 2017; 34: 85-6.

4. Solak B, Dikicier BS, Cosansu NC, Erdem T. Neutrophil to lymphocyte ratio in patients with vitiligo. Adv Dermatol Allergo 2017; 34: 468-70.

5. Ataş H, Cemil BÇ, Kurmuş GI, Gönül M. Assessment of systemic inflammation with neutrophil-lymphocyte ratio in lichen planus. Adv Dermatol Allergol 2016; 33: 188-92.

6. Nacaroglu HT, Isguder R, Bahceci SE, et al. Can mean platelet volume be used as a biomarker for asthma? Adv Dermatol Allergol 2016; 33: 182-7.

7. Strober B, Teller C, Yamauchi P, et al. Effects of etanercept on $\mathrm{C}$-reactive protein levels in psoriasis and psoriatic arthritis. Br J Dermatol 2008; 159: 322-30.

8. Unal M, Kuçuk A, Unal GU, et al. Psoriasiste ortalama trombosit hacmi, nötrofil/lenfosit oranı ve trombosit/lenfosit oranı. Türkderm 2015; 49: 112-6.

9. Turkmen K, Erdur FM, Ozcicek F, et al. Platelet-to-lymphocyte ratio better predicts inflammation than neutrophil-to-lymphocyte ratio in end-stage renal disease patients. Hemodial Int 2013; 17: 391-6.

10. Hirschfield GM, Pepys MB. C-reactive protein and cardiovascular disease: new insights from an old molecule. QJM 2003; 96: 793-807.

11. Kılıç $\mathrm{S}$, Reşorlu H, Işik S, et al. Association between mean platelet volume and disease severity in patients with psoriasis and psoriatic arthritis. Adv Dermatol Allergol 2017; 34 : 126-30.

12. Işik S, Kılıç S, Öğretmen Z, et al. The correlation between the psoriasis area severity index and ischemia-modified albumin, mean platelet volume levels in patients with psoriasis. Adv Dermatol Allergol 2016; 33: 290-3.

13. Boehncke WH, Sch€on MP. Psoriasis. Lancet 2015; 386: 983-94.

14. Krueger G, Ellis CN. Psoriasis - recent advances in understanding its pathogenesis and treatment. J Am Acad Dermatol 2005; 53: 94-100

15. Sen BB, Rifaioglu EN, Ekiz O, et al. Neutrophil to lymphocyte ratio as a measure of systemic inflammation in psoriasis. Cutan Ocul Toxicol 2014; 33: 223-7.
16. Rocha-Pereira P, Santos-Silva A, Rebelo I, et al. The inflammatory response in mild and in severe psoriasis. Br I Dermatol 2004; 150: 917-28.

17. Yamanaka K, Umezawa Y, Yamagiwa A, et al. Biologic therapy improves psoriasis by decreasing the activity of monocytes and neutrophils. J Dermatol 2014; 41: 679-85.

18. Boyraz I, Koç B, Boyacı A, et al. Ratio of neutrophil/lymphocyte and platelet/lymphocyte in patient with ankylosing spondylitis that are treating with anti-TNF. Int J Clin Exp Med 2014; 7: 2912-5

19. Gasparyan AY, Sandoo A, Stavropoulos-Kalinoglou A, Kitas GD. Mean platelet volume in patients with rheumatoid arthritis: the effect of anti-TNF-alpha therapy. Rheumatol Int 2010; 30: 1125-9.

20. Sengül E, Özbay M, Topcu I. Relationship between neutrophil-to-lymphocyte ratio and prognosis in patients with deep neck space infection. Dicle Med J 2016; 43: 126-9.

21. Erek Toprak A, Ozlu E, Uzuncakmak TK, et al. Neutrophil/ lymphocyte ratio, serum endocan, and nesfatin- 1 levels in patients with psoriasis vulgaris undergoing phototherapy treatment. Med Sci Monit 2016; 22: 1232-7.

22. Asahina A, Kubo N, Umezawa Y, et al. Neutrophil-lymphocyte ratio, platelet-lymphocyte ratio and mean platelet volume in Japanese patients with psoriasis and psoriatic arthritis: response to therapy with biologics. J Dermatol 2017; 44: $1112-21$.

23. Kaplan ZS, Jackson SP. The role of platelets in atherothrombosis. Hematology Am Soc Hematol Educ Program 2011; 2011: 51-61.

24. Kwiek B, Narbutt J, Sysa-Jędrzejowska A, et al. Long-term treatment of chronic plaque psoriasis with biological drugs can control platelet activation: targeting the bridge between inflammation and atherothrombosis. Adv Dermatol Allergol 2017; 34: 131-7.

25. Kılıç S, Işık S, Hiz MM, et al. The ischemia modified albumin and mean platelet volume levels in patients with Behçet's disease. Adv Dermatol Allergol 2016; 33: 345-8.

26. Canpolat F, Akpinar H, Eskioğlu F. Mean platelet volume in psoriasis and psoriatic arthritis. Clin Rheumatol 2010; 29: 325-8.

27. Cerman AA, Karabay EA, Altunay IK. The evaluation of the relationship between the response of systemic treatment with C-reactive protein and neutrophil lymphocyte ratio in psoriasis patients: a preliminary study. Turkiye Klinikleri J Dermatol 2016; 26: 71-5.

28. Strober BE, Poulin Y, Teller C, et al. Changes in C-reactive protein in patients with moderate- to-severe psoriasis switched to adalimumab therapy after suboptimal response to etanercept, methotrexate or phototherapy. J Eur Acad Dermatol Venereol 2014; 28: 1701-6.

29. Asahina A, Umezawa Y, Yanaba K, Nakagawa H. Serum C-reactive protein levels in Japanese patients with psoriasis and psoriatic arthritis: long-term differential effects of biologics. J Dermatol 2016; 43: 779-84. 